Review Article

\title{
New biotechnological tools to accelerate scab-resistance trait transfer to apple
}

\author{
Roberta Cusin ${ }^{1}$, Luís Fernando Revers ${ }^{2}$ and Felipe dos Santos Maraschin ${ }^{1}$ \\ ${ }^{1}$ Plant Physiology Laboratory, Departamento de Botânica, Instituto de Biociências, \\ Universidade Federal do Rio Grande do Sul, Porto Alegre, RS, Brazil. \\ ${ }^{2}$ Laboratory of Plant Molecular Genetics, Centro Nacional de Pesquisa de Uva e Vinho, \\ Empresa Brasileira de Pesquisa Agropecuária, Bento Gonçalves, RS, Brazil.
}

\begin{abstract}
Apple is a fruit crop cultivated worldwide. Apple orchards are exposed to a diverse set of environmental and biological factors that affect the productivity and sustainability of the culture. Many of the efforts and costs for apple production rely on reducing the incidence of fungal diseases, and one of the main diseases is apple scab caused by the fungus Venturia inaequalis. The economic impact of scab on apple productivity has guided many breeding programs to search for cultivars resistant to apple scab. Introgression from wild relatives has been successful to some extent, and genetic engineering for resistant cultivars has even been employed. This review presents the techniques used to the present time to obtain pathogen-resistant apple cultivars and introduces new biotechnological approaches based on plant plasmids that show promising results for delivering genetic traits with a short-term perspective.
\end{abstract}

Keywords: Malus, Venturia inaequalis, biotic stress, transformation.

Received: February 25, 2016; Accepted: July 18, 2016.

\section{Introduction}

The cultivated apple belongs to the Rosaceae family, Maloideae subfamily, and the farmed apple tree is known as Malus x domestica Borkhausen (Harris et al., 2002). Apple orchards are susceptible to several pathogens. The main diseases that affect apple production include apple scab, fire blight, powdery mildew, and the juniper rusts (including cedar-apple rust, cedar quince rust, and cedar-hawthorn rust), which are all caused by fungal agents and their control is achieved mainly through chemical control (Sutton, 1996; Igarashi et al., 2016). However, their inadequate or excessive use may contaminate the environment and harm human health. Furthermore, prolonged use of these products may result in selection pressure of the pathogenic agent, inducing the appearance of resistant isolates (Bonaterra et al., 2012).

Plants possess natural defenses against a diverse range of pathogens. The Malus genus has coevolved with its pathogens, and many accessions harbor resistance genes that are exploited for introgression from wild relatives in apple breeding programs (Kumar et al., 2010; Laurens et al., 2011). The breeding of apples resistant to scab is a ge-

Felipe dos Santos Maraschin. Plant Physiology Laboratory. Instituto de Biociências. Departamento de Botânica. Universidade Federal do Rio Grande do Sul (UFRGS), Av. Bento Gonçalves 9500, Prédio 43423, sala 224, CEP 91501-970 Porto Alegre, RS, Brazil. E-mail: felipe.maraschin@ufrgs.br netically-based strategy. Scab is the most important disease in terms of economic cost in apple orchards worldwide. $V$. inaequalis develops in the fallen leaves of apple trees. The infection starts in the spring and early summer. The pathogenic phase starts with the germination of ascospores (sexual spores), which serve as the primary source of inoculum. Conidia (asexual spores) serve as a source for secondary infection. Several cycles of conidial production and secondary infections occur within a single apple-growing season (MacHardy et al., 2001). Scab causes deformation in the shape and size of the fruits, leaves, and premature fall of the fruit. The breeding programs follow, in general, a common strategy, which establishes a series of backcrossings between resistant hybrids and susceptible commercial cultivars. Usually, the source of resistance genes comes from sexually compatible wild apple relatives. This process is very time-consuming and demands cultivation of several generations to recover near-isogenic lines of high commercial value expressing the desired trait. In the apple, selfincompatibility turns breeding into an even more difficult endeavor as the elite varieties might not be recovered by crossing. As a result, strategies able to directly transfer traits to elite cultivated varieties would drastically accelerate the process. 


\section{The genetics of scab resistance}

The $V$. inaequalis-Malus interaction has been known for a long time (Boone and Keitt, 1957; Williams and Shay, 1957). Since the early days of apple resistance breeding, several sources of resistance genes have been described in the apple germplasms (Bus et al., 2011).

The interaction between $V$. inaequalis and Malus species occurs in accordance to the gene-for-gene concept (Flor, 1971). Many resistance (R) genes have been identified in Malus mapping populations or from wild relatives among others (Jha et al., 2009; Bus et al., 2011). In this regard, the $V f$ locus of Malus floribunda was the first one to successfully undergo the process of introgression in Malus domestica. The $V f$ locus has been widely adopted in improvement programs directed towards the resistance against apple tree scab (Crosby et al., 1992; Vinatzer et al., 2001; Xu and Korban, 2002).

A cluster of four receptor-like sequences has been identified at the $V f$ locus, and these sequences are homologs to the $C f$ resistance genes from tomato. Three of the $V f$ genes, designated $V f a 1, V f a 2$, and $V f a 4$, have intact ORFs, whereas $V f a 3$ is truncated and considered a pseudogene (Xu and Korban, 2002). The overexpression of the Hcrvf2 ( $V f a 2$ ) gene, under the control of the constitutive promoter CaMV35S, was sufficient to confer scab resistance to the susceptible apple cultivar Gala (Belfanti et al., 2004). However, this resistance is specific to $V$. inaequalis races 1 to 5 , but not towards race 6 (Jha et al., 2009). It was also shown that when the $V f a 2$ gene was expressed under the control of its own promoter, it conferred partial resistance to $V$. inaequalis in Galaxy and McIntosh cultivars ( $\mathrm{Xu}$ and Korban, 2002). In addition, the $V f a l$ gene is capable of conferring partial resistance in susceptible cultivars races 1 to 5. This shows that these two genes are involved in resistance to $V$. inaequalis, while the $V f a 4$ gene is not involved in resistance (Malnoy et al., 2008).

Breeding programs have extensively studied resistance genes against apple scab worldwide. A new naming system was proposed based on the international standard Arabidopsis genes. The names of major $R$ genes start with $R$ and contain an abbreviation of the pathogen $V$. inaequalis, resulting in the locus general prefix $R v i$. To date, 17 genes have been described: $V g$ (Rvil) was identified in the cultivar Golden Delicious; Vh2 (Rvi2) in TSR34T15; Vh3 (Rvi3) in Geneva; $V h 4, V x$ and $V r l$ (Rvi4) in TSR33T239; $V m$ (Rvi5) in 9-AR2T196; Vf (RviO) and Vfh (Rvi7) in Malus floribunda; Vh8 (Rvi8) in M. sieversii; Vdg (Rvi9) in $\mathrm{K} 2 ; \mathrm{Va}($ Rvi10) in A723-6 ; Vbj (Rvi11) in M. baccata jackii; $V b$ (Rvil2) in Hansen's baccata; Vd (Rvil3) in Durello di Forlì; Vdr1 (Rvi14) in Dulmener Rosenapfel ${ }^{\mathrm{b}}$; $V r 2$ (Rvi15) in GMAL 2473; Vmis (Rvil6) in MIS op 93.051 G07-098 ${ }^{\mathrm{b}}$, and Val (Rvil7) in Antonovka APF22 ${ }^{\mathrm{b}}$ [7] (Bus et al., 2011).

\section{Transformation and genetic modification of apple}

Traditional apple breeding is a slow process, because of the long juvenile phase and high degree of genetic heterozygosity present in this perennial fruit tree. For the breeding of almost all scab-resistant cultivars, the focus has been mainly on the $V f 2$ gene (Gessler and Pertot, 2012). Once scab resistance still primarily relies on $V f$, genes from other sources will be needed to overcome resistance breakdown over time. Alongside the classical breeding programs, in the past decades, several apple genetic modification strategies have been developed for obtaining scab-resistant varieties. Recent advances in genomics have allowed apple genetic transformation to become a promising technology for the acceleration of development of elite cultivars of apple (Gessler and Patocchi, 2007).

The resistance gene HcrVf2/Rvi6 was transferred by Agrobacterium tumefaciens to susceptible apple cultivars (Barbieri et al., 2003; Belfanti et al., 2004; SilfverbergDilworth et al., 2005; Malnoy et al., 2008), and further attempts even led to the attainment of cisgenic resistant plants carrying HcrVf2/Rvi6 (Joshi et al., 2011; Vanblaere et al., 2011,2014) and not carrying any foreign DNA nor selection markers (Krens et al., 2015). Several other scab resistance genes have been mapped; however, only Vr2/Rvi15 (Bus et al., 2011) has been functionally characterized, and this has conferred scab resistance to the 'Gala' cultivar (Schouten et al., 2014).

Although these approaches have successfully delivered the introgression of the $V f 2$ gene, the sole use of $V f 2$ in scab-resistance breeding programs and in GM plants is not advisable. The appearance of new virulent fungal races is continuous in a perennial orchard, and combining diverse disease resistance mechanisms could help to improve disease management strategy. As stated by Gessler and Pertot (2012), the major bottleneck for new resistance breeding is the lack of cloned resistance genes in Malus. From the publication of the first draft genome of apple in 2010 (Velasco et al., 2010), there is still much work remaining to associate resistance phenotypes to linkage groups, and finally to cloned resistance genes.

Many efforts have focused on the utilization of genes from other source species in order to confer more broad resistance traits not dependent on pathogen race recognition. Some attempts in this direction have been reported using heterologous genes, known for their antifungal activity, such as genes from the biocontrol fungus Trichoderma atroviride (formerly T. harzianum). This fungus produces many chitinolytic enzymes including endochitinase, which randomly cleaves chitin, a major component of the fungal cell wall. One Trichoderma atroviride endochitinase encoded by the ech 42 gene inhibits the germination of spores and hyphae elongation. One study obtained several transgenic lines of the scab-susceptible apple McIntosh cultivar 
with varying expression levels of the ech 42 gene (Bolar et al., 2000). Some transgenic lines showed an increased resistance to $V$. inaequalis with constitutive expression of fungal endochitinase. However, these lines with high endochitinase activity displayed reduced plant vigor. Similar results were also observed when the ech 42 gene was introduced in Galaxy and Ariane apple cultivars alone or co-transformed with the $T$. atroviride exo chitinase nag70 (Bolar et al., 2001). This reduction in plant vigor seems to be related to the high lignin content and higher peroxidase and glucanase activities in the transgenic lines (Faize et al., 2003).

The antifungal wheat protein puroinduline $\mathrm{B}(\operatorname{pin} B)$, a member of plant lipid transfer proteins (LTPs), was expressed in Ariane (an apple cultivar carrying $V f$ ), which is resistant to races 1-5 $\mathrm{V}$. inaequalis, and Galaxy, which is susceptible to all races. In these experiments, both Galaxy and Ariane $\operatorname{pin} B$ overexpressors displayed enhanced resistance to scab (Faize et al., 2004). This suggests that the combination of diverse resistance strategies can improve the field performance of these plants where they are exposed to a wide diversity of pathogens. Besides apple scab, genes conferring resistance to fire blight (Liu et al., 2001; Borejsza-Wysocka et al., 2007; Malnoy et al., 2007; Broggini et al., 2014), Alternaria blotch (Fan et al., 2011), and powdery mildew (James et al., 2004; Caffier and Parisi, 2007; Chen et al., 2012) have been described, and these could be used in conjunction with scab resistant genes in order to obtain multiple resistance via gene pyramiding. Many genes could be readily tested in transient assays with virus-derived vectors instead of generating apple transgenic plants for testing each gene.

Despite that genetic and genomic studies have progressed to a very advanced level in apple, the application of the acquired knowledge for marker assisted breeding (MAB) remains limited to a few breeding programs, probably due to difficulties associated with its implementation (Bassil and Lewers, 2009). MAB requires both the development and application of a complex knowledge and access to well-equipped genotyping facilities. Therefore, $\mathrm{MAB}$ is being used mainly for pyramiding monogenetically inherited traits like fruit quality and disease resistance (apple scab, powdery mildew and fire blight) with the purpose of generating homozygous breeding elite lines that can be used in further crosses (Baumgartner et al., 2015). During the course of DNA markers development in apple, scab resistance has preceded that of other traits and have evolved from dominant RAPD (Random Amplified Polymorphic DNA) markers (Koller et al., 1994) to co-dominant microsatellites and, more recently, to SingleNucleotide Polymorphism (SNP) markers (Patocchi et al., 2009, Igarashi et al., 2016, Jänsch et al., 2015). In the last decade, genomic sequences and chromosome maps of various cultivars have become available, allowing the development of large SNP arrays (Bianco et al., 2014, Bianco et al.,
2016, Baumgartner et al., 2016), turning these markers into the best choice for high-throughput analysis, reducing the costs of MAB strategies. The SNP markers are expected to provide solutions to several problems of apple breeding such as to increase the precision of selection, the lengthy juvenility and the large field space required for growing populations. In order to advance the selection of new apple cultivars, another challenge is to shorten the long-term apple tree juvenility. This juvenile phase can last between 4 and 10 years. The first fast cycle breeding approach using the effective introgression of BpMADS4, a flowering gene from European silver birch (Betula pendula Roth.) resulted in an early flowering phenotype in 'Pinova' (Flachowsky et al., 2011), 'Gala', 'Mitchgla Gala', and 'Santana' (Weigl et al., 2015) cultivars. Besides, silencing of the floral repressor MdTFL1 (TERMINALFLOWER1) gene inhibits vegetative growth and accelerates flower development (Flachowsky et al., 2012). The transformation and plant regeneration process is a lengthy and costly process, usually with a low efficiency rate, but many efforts have made it feasible in apple, with a large set of transgenic lines described (Aldwinckle and Malnoy, 2009). Commercial apple varieties are difficult to breed with new characteristics, as each time one introduces a new trait by crossing, a completely new genotype with new characteristics will be generated. Self-incompatibility in the apple does not allow simple backcrossings, and time-consuming pseudobackcrossings lead to a delay in trait delivery. Consequently, biotechnological tools able to transfer resistance into already-cultivated cultivars would be an excellent opportunity to accelerate resistance breeding.

Moreover, if several genes have to be crossed in order to achieve durable resistance to multiple pathogens, then achieving such a multigenic combination into apple by conventional breeding becomes a nearly impossible task.

\section{Technological strategies using transient virus}

An alternative method to achieve genetic transformation and transgenic plants for trait delivery relies on plant viruses. Apple latent spherical virus (ALSV) is an infectious plant virus capable of spreading through infected cells without inducing any diseases. Initially used for VIGS (Virus-Induced Gene Silencing) experiments in herbaceous plants, the ALSV vector is capable of sustaining uniform silencing phenotypes and persisting for several months (Igarashi et al., 2009). Apple seedlings were inoculated with rbcS-ALSV, and the phenotype of systemic silencing persisted for more than three months in most of the infected plants (Sasaki et al., 2011). Thus, the VIGS system using ALSV vectors can induce both VIGS and gene overexpression in apple seedlings as efficiently and persistently as in herbaceous plants (Yamagishi et al., 2014). Furthermore, ALSV has been modified to express genes that confer desirable traits such as early flowering (Sasaki et al., 2011; Yamagishi et al., 2011). A construct of a modified 
ALSV vector (ALSV-AtFT/MdTLF1-1) designed to express the Arabidopsis thaliana florigen protein FLOWERING LOCUS $\mathrm{T}$ (AtFT) and to suppress the expression of TERMINAL FLOWER 1 (MdTFL1-1) was delivered by biolistic inoculation to germinated apple seeds where it was able to reduce the flowering period for approximately one year. In addition, it was verified that the ALSV vector was not transmitted to the majority of the successive progenies (Yamagishi et al., 2014). This technique might have a major impact on the acceleration of breeding programs, as it does not involve the genetic modification of the host plant and allows both overexpression and silencing of trait genes. One of the major drawbacks of this system is the use of a full-length infectious virus that needs to be maintained and propagated in host plants. The insert size limitation is usually related to the carrying capacity of the viral genomes and, in addition, the method of administration relies on biolistics of the mature viral RNA, which can be methodologically laborious.

\section{New perspectives: plant episomal plasmids}

During the past decade, many advances have occurred in the plant biotechnology field. For perennial plants, one of the most interesting and overlooked processes has been the expression system based on episomal plant plasmids. The system, called IL-60, is derived from the Tomato Yellow Leaf Curls Virus (TYLCV), a monopartite ssDNA geminivirus with a broad host range (Peretz et al., 2007). IL-60 is based on a modified virus that can be mechanically administered to plants and has all of the symptom-causing ORFs removed or mutated to render a dsDNA plasmid able to be replicated in plant cells as an episomal plasmid. The viral regions essential for gene expression and cell-to-cell movement are maintained, and specific trait genes can be directly introduced into plants. The IL-60 plasmids will replicate, spread to other tissues, and eventually express the trait gene throughout the plant body in a stable manner for the full life cycle of the treated plant, and many species are compatible, including woody fruit trees such as grapevine, citrus, and olive. As observed for the ASLV vectors (Yamagishi et al., 2014), the TYLCV-derived plasmids are not heritable, and the progeny will be devoid of the plasmid DNA. Further development of the system allowed the expression of a full bacterial operon in tomato plants (Mozes-Koch, et al., 2012). The construction was somehow processed from a polycistronic RNA, and the metabolite pyrrolnitrin synthesized from the four introduced bacterial genes was detected by HPLC in the treated plants. The tomato plants able to synthesize the antifungal pyrrolnitrin displayed disease resistance to Rhizoctonia solani. The system has been updated, and only minimal regions of the TYLCV genome, essential for the maintenance and movement of the plasmids, were kept, resulting in two plasmids named pIR and p1470 (Gover et al., 2014). An Israeli company named Morflora (http://www.moreflora.com/) retains a patent for the use of the IL- 60 plasmids by the name of TraitUP ${ }^{\mathrm{TM}}$.

This technique was already successfully tested in apple with transient assays for the characterization of Malus COP1 orthologs (Li et al., 2012), which opens an alternative for the functional analysis of apple genes in a homologous system. From our side, we have performed successful preliminary tests using apple plants and the IL-60 plasmids for expression of reporter genes such as GFP. Apple plants from the Gala cultivar treated with pIR-GFP plus p1470 displayed a broad, stable, and strong GFP expression that spread through all tissues progressively and remained stable even six months after treatment with the plasmid DNA (data not shown). The compatibility of such plant plasmids with apple allows us to use it as a genetic platform for transferring scab resistance genes (such as $V f 2$ ), as well as other genes of biotechnological interest, to elite apple cultivars. The genes seem to be stably expressed throughout the plant's development. This method eliminates the need for crosses and plant transformation turning into an immediate genetic trait transfer tool.

One exciting new possibility for genome editing and trait introgression appeared after the discovery of CRISPRs/Cas9 (Jinek et al., 2012; Cong et al., 2013) nucleases, which need to be transiently expressed only to create site-specific double strand breaks (DSBs). Plant episomal plasmids can be engineered to deliver these tailored nucleases to plants, as described for Agrobacterium binary vectors (Baltes et al., 2014; Kumar and Jain, 2014; Ali et al., 2015), and gene-specific modifications can be obtained without creating a transgenic plant. Recently, successful targeted mutagenesis has been obtained in plants with DNA-free preassembled CRISPR-Cas9 (Woo et al., 2015), which would avoid the generation of transgenic cells and accelerate product development. A significantly increased availability of genomic information for fruit species expands this possibility among many cultures, and a feasible expression system is essential for the application of these techniques (Yin et al., 2015). Many relevant traits in apples are dependent on loss-of-function mutations, such as ripening (Dandekar et al., 2004), self-incompatibility (Broothaerts et al., 2004), allergenicity (Gilissen et al., 2005), and fire blight resistance (Borejsza-Wysocka et al., 2004), among many others (Bulley et al., 2007). Recently, engineered point-mutations in the COI1 JA co-receptor rendered coronatine-insensitive Arabidopsis plants showing enhanced resistance to pathogenic bacteria (Zhang et al., 2015). A proof-of-concept study utilizing CRISPR/Cas9 introduced recessive mutations in Arabidopsis eIF(iso) $4 E$ locus for conferring resistance to potyvirus (Pyott et al., 2016). Similar mutations could be delivered by transient expression of tailored site-specific nucleases into the apple breeding germplasm to develop more scab-resistant cultivars. 
The new developments achieved in the recent past years have opened exciting new possibilities for fast trait delivery in woody fruit species (Nagamangala Kanchiswamy et al., 2015). Besides genetic transformation, which has been very successful in apple despite the hurdles of plant regeneration, easier, faster, and readily approachable new options are available for breeders worldwide. The long juvenile cycles, the large population screens, the high-throughput phenotyping/genotyping, and successive crossings are still essential to any breeding program, but we can accelerate and facilitate the process with the technologies that are just waiting to be exploited. These episomal expression systems, based on modified viruses, may enable the expression of stable traits that can be introduced by treating scions prior to grafting using elite genotypes, bypassing the backcrossing events to recover the original genetic background. Concerns regarding biosafety and transgene escapes are still to be assessed, but due to the lack of heritability of the episomal DNA, this control might be easier than pollen-mobile genetic contamination derived from genetically modified plants.

\section{Acknowledgments}

The authors would like to acknowledge the financial support from Conselho Nacional de Desenvolvimento Científico e Tecnológico (CNPq) and Embrapa (SEG 12/2012 - Prioridades do Portfólio Mudanças Climáticas, Project 02.12.12.003.00.00).

\section{References}

Aldwinckle H and Malnoy M (2009) Plant regeneration and transformation in the Rosaceae. Transgenic Plant J 3:1-39.

Ali Z, Abul-Faraj A, Li L, Ghosh N, Piatek M, Mahjoub A, Aouida M, Piatek A, Baltes NJ, Voytas DF, et al. (2015) Efficient virus-mediated genome editing in plants using the CRISPR/Cas9 system. Mol Plant 8:1288-1291.

Baltes NJ, Gil-Humanes J, Cermak T and Voytas DF (2014) DNA replicons for plant genome engineering. Plant Cell 26:151-163.

Barbieri M, Belfanti E, Trtarino S, Vinatzer BA, Sansavini S, Silfverberg-Dilworth E, Gianfranceschi L, Hermann D, Patocci A and Gessler C (2003) Progress of map-based cloning of the $V f$-resistance gene and functional verification: Preliminary results from expression studies in transformed apple. Hort Science 38:329-331.

Bassil N and Lewers K (2009) Genomics opportunities, new crops and new products. In: Folta KM and Gardiner SE (eds), Genetics and Genomics of Rosaceae Vol. 6, Plant Genetics and Genomics: Crops and Models. Springer, New York, p. $55-70$.

Baumgartner IO, Patocchi A, Frey JE, Peil A and Kellerhals M (2015) Breeding elite lines of apple carrying pyramided homozygous resistance genes against apple scab and resistance against powdery mildew and fire blight. Plant Mol Biol Rep 33:1573-1583.

Baumgartner IO, Kellerhals M, Costa F, Dondini L, Pagliarani G, Gregori R, Tartarini S, Leumann L, Laurens F and Patocchi
A (2016) Development of SNP-based assays for disease resistance and fruit quality traits in apple (Malus domestica Borkh.) and validation in breeding pilot studies. Tree Genet Genomes 12:35.

Belfanti E, Silfverberg-Dilworth E, Tartarini S, Patocchi A, Barbieri M, Zhu J, Vinatzer BA, Gianfranceschi L, Gessler $\mathrm{C}$ and Sansavini S (2004) The HcrVf2 gene from a wild apple confers scab resistance to a transgenic cultivated variety. Proc Natl Acad Sci USA 101:886-890.

Bianco L, Cestaro A, Sargent DJ, Banchi E, Derdak S, Di Guardo M, Salvi S, Jansen J, Viola R, Gut I, et al. (2014) Development and validation of a $20 \mathrm{~K}$ single nucleotide polymorphism (SNP) whole genome genotyping array for apple (Malus domestica Borkh). PLoS One 10:e110377.

Bianco L, Cestaro A, Linsmith G, Muranty H, Denancé C, Théron A, Poncet C, Micheletti D, Kerschbamer E, Di Pierro EA, et al. (2016) Development and validation of the Axiom $\left({ }^{\circledR}\right)$ Apple480K SNP genotyping array. Plant J 86:62-74.

Bolar JP, Norelli JL, Wong KW, Hayes CK, Harman GE and Aldwinckle HS (2000) Expression of endochitinase from Trichoderma harzianum in transgenic apple increases resistance to apple scab and reduces vigor. Phytopathology 90:72-77.

Bolar JP, Norelli JL, Harman GE, Brown SK and Aldwinckle HS (2001) Synergistic activity of endochitinase and exochitinase from Trichoderma atroviride (T. harzianum) against the pathogenic fungus (Venturia inaequalis) in transgenic apple plants. Transgenic Res 10:533-543.

Bonaterra A, Badosa E, Cabrefiga J, Francés J and Montesinos E (2012) Prospects and limitations of microbial pesticides for control of bacterial and fungal pomefruit tree diseases. Trees 26:215-226.

Boone DM and Keitt GW (1957) Venturia inaequalis (Cke.) Wint. XII. Genes controlling pathogenicity of wild-type lines. Phytopathology 47:403-409.

Borejsza-Wysocka EE, Malnoy M, Meng X, Bonasera JM, Nissinen RM, Kim JF, Beer SV and Aldwinckle HS (2004) Silencing of apple proteins that interact with DspE, a pathogenicity effector from Erwinia amylovora, as a strategy to increase resistance to fire blight. Acta Hort 663:469-474.

Borejsza-Wysocka EE, Malnoy M, Kim WS, Geider K, Beer SV and Aldwinckle HS (2007) Expression of Phi-Ealh phage depolymerase gene with constitutive and inducible promoters, translation enhancer and signal sequence in transgenic apple plants increases resistance to fire blight. Acta Hortic 738:273-276.

Broggini GA, Wöhner T, Fahrentrapp J, Kost TD, Flachovsky H, Peil A, Hanke M, Richter K, Patocchi A and Gessler C (2014) Engineering fire blight resistance into the apple cultivar 'Gala' using the $F B \_M R 5$ CC-NBS-LRR resistance gene of Malus x robusta 5. Plant Biotechnol J 12:728-733.

Broothaerts W, Keulemans J and Van Nerum I (2004) Self-fertile apple resulting from S-RNase gene silencing. Plant Cell Rep 22:497-501.

Bulley SM, Malnoy M, Atkinson RG and Aldwinckle HS (2007) Transformed apples: Traits of significance to growers and consumers. Transgenic Plant J 1:267-279.

Bus VG, Rikkerink EH, Caffier V, Durel CE and Plummer KM (2011) Revision of the nomenclature of the differential host-pathogen interactions of Venturia inaequalis and Malus. Annu Rev Phytopathol 49:391-413. 
Caffier V and Parisi L (2007) Development of apple powdery mildew on sources of resistance to Podosphaera leucotricha, exposed to an inoculum virulent against the major resistance gene Pl-2. Plant Breeding 126:319-322.

Chen XK, Zhang JY, Zhang Z, Du XL, Du BB and Qu SC (2012) Overexpressing MhNPRl in transgenic Fuji apples enhances resistance to apple powdery mildew. Mol Biol Rep 39:8083-8089.

Cong L, Ran FA, Cox D, Lin S, Barretto R, Habib N, Hsu PD, Wu X, Jiang W, Marraffini LA, et al. (2013) Multiplex Genome Engineering Using CRISPR/Cas Systems. Science 339:819-823.

Crosby JA, Janick J, Pecknold PC, Korban SS, O'Connon PA, Ries SM, Goffreda J and Voordeckers A (1992) Breeding apples for scab resistance: 1945-1990. Fruit Varieties J 46:145-166.

Dandekar AM, Teo G, Defilippi BG, Uratsu SL, Passey AJ, Kadel AA, Stow JR, Colgan RJ and James DJ (2004) Effect of down-regulation of ethylene biosynthesis on fruit flavor complex in apple fruit. Transgenic Res 13:373-384.

Faize M, Malnoy M, Dupuis F, Chevalier M, Parisi L and Chevreau E (2003) Chitinases of Trichoderma atroviride induce scab resistance and some metabolic changes in two cultivars of apple. Phytopathology 93:1496-1504.

Faize M, Sourice S, Dupuis F, Parisi L, Gautier MF and Chevreau E (2004) Expression of wheat puroindoline-b reduces scab susceptibility in transgenic apple (Malus $x$ domestica Borkh.). Plant Sci 167:347-354.

Fan H, Wang F, Gao H, Wang L, Xu J and Zhao Z (2011) Pathogen-induced MdWRKY1 in 'Qinguan' apple enhances disease resistance. J Plant Biol 54:150-158.

Flachowsky H, Le Roux PM, Peil A, Patocchi A, Richter K and Hanke MV (2011) Application of a high-speed breeding technology to apple (Malus domestica) based on transgenic early flowering plants and marker-assisted selection. New Phytol 192:364-377.

Flachowsky H, Szankowski I, Waidmann S, Peil A, Tränkner C and Hanke MV (2012) The MdTFL1 gene of apple (Malus X domestica Borkh.) reduces vegetative growth and generation time. Tree Physiol 10:1288-1301.

Flor HH (1971) Current status of the gene-for-gene concept. Annu Rev Phytopathol 9:275-296.

Gessler C and Patocchi A (2007) Recombinant DNA Technology in apple. Adv Biochem Eng Biotechnol 107:113-132.

Gessler C and Pertot I (2012) Vf scab resistance of Malus. Trees 26:95-108.

Gilissen LJ, Bolhaar ST, Matos CI, Rouwendal GJ, Boone MJ, Krens FA, Zuidmeer L, Van Leeuwen A, Akkerdaas J, Hoffmann-Sommergruber K, et al. (2005) Silencing the major apple allergen Mal d 1 by using the RNA interference approach. J Allergy Clin Immunol 115:354-369.

Gover O, Peretz Y, Mozes-Koch R, Maori E, Rabinowitch HD and Sela I (2014) Only minimal regions of tomato yellow leaf curl virus (TYLCV) are required for replication, expression and movement. Arch Virol 159:2263-2274.

Harris SA, Robinson JP and Juniper BE (2002) Genetic clues to the origin of the apple. Trends Genet 18:426-430.

Igarashi A, Yamagata K, Sugai T, Takahashi Y, Sugawara E, Tamura A, Yaegashi H, Yamagishi N, Takahashi T, Isogai M, et al. (2009) Apple latent spherical virus vectors for reliable and effective virus-induced gene silencing among a broad range of plants including tobacco, tomato, Arabidopsis thaliana, cucurbits, and legumes. Virology 386:407-416.

Igarashi M, Hatsuyama Y, Harada T and Fukasawa-Akada T (2016) Biotechnology and apple breeding in Japan. Breeding Sci 66:18-33.

James CM, Clarke JB and Evans KM (2004) Identification of molecular markers linked to the mildew resistance gene $\mathrm{Pl}-\mathrm{d}$ in apple. Theor Appl Genet 110:175-181.

Jänsch M, Broggini GA, Weger J, Bus VG, Gardiner SE, Bassett $\mathrm{H}$ and Patocchi A (2015) Identification of SNPs linked to eight apple disease resistance loci. Mol Breed 35:45.

Jha G, Thakur K and Thakur P (2009) The Venturia apple pathosystem: Pathogenicity mechanisms and plant defense responses. J Biomed Biotechnol 2009:1-10.

Jinek M, Chylinski K, Fonfara I, Hauer M, Doudna JA and Charpentier E (2012) A programmable dual-RNA-guided DNA endonuclease in adaptive bacterial immunity. Science 337:816-821.

Joshi SG, Schaart JG, Groenwold R, Jacobsen E, Schouten HJ and Krens FA (2011) Functional analysis and expression profiling of HcrVfl and HcrVf2 for development scab resistant cisgenic and intragenic apples. Plant Mol Biol 75:579-591.

Koller B, Gianfranceschi L, Seglias N, McDermott J and Gessler C (1994) DNA markers linked to the Malus floribunda 821 scab resistance. Plant Mol Biol 26:597-602.

Krens FA, Schaart JG, van der Burgh AM, Tinnenbroek-Capel IE, Groenwold R, Kodde LP, Broggini GA, Gessler C and Schouten HJ (2015) Cisgenic apple trees; development, characterization, and performance. Front Plant Sci 6:1-11.

Kumar S, Volz R, Alspach P and Bus V (2010) Development of a recurrent apple breeding programme in New Zealand: A synthesis of results, and a proposed revised breeding strategy. Euphytica 173:207-222.

Kumar V and Jain M (2014) The CRISPR-Cas system for plant genome editing: Advances and opportunities. J Exp Bot 66:47-57.

Laurens F, Durel CE, Patocchi A, Peil A, Salvi S, Tartarini S, Velasco R and van de Weg E (2011) Review on apple genetics and breeding programmes and presentation of a new European initiative to increase fruit breeding efficiency. J Fruit Sci 27:102-107.

Li YY, Mao K, Zhao C, Zhao XY, Zhang HL, Shu HR and Hao YJ (2012) MdCOP1 Ubiquitin E3 Ligases interact with MdMYB1 to regulate light-induced anthocyanin biosynthesis and red fruit coloration in apple. Plant Physiol 160:1011-1022.

Liu Q, Ingersoll J, Owens L, Salih L, Meng R and Hammerschlag F (2001) Response of transgenic Royal Gala apple (Malus domestica Borkh.) shoots carrying a modified cecropin MB39 gene, to Erwinia amylovora. Plant Cell Rep 20:306-312

MacHardy WE, Gadoury DM and Gessler C (2001) Parasitic and biological fitness of Venturia inaequalis: Relationship to disease management strategies. Plant Dis 85:1036-1052.

Malnoy M, Jin Q, Borejsza-Wysocka EE, He SY and Aldwinckle HS (2007) Overexpression of the apple MpNPR1 gene confers increased disease resistance in Malus domestica. Mol Plant-Microbe Interact 20:1568-1580.

Malnoy M, Xu M, Borejsza-Wysocka E, Korban SS and Aldwinckle HS (2008) Two receptor-like genes, Vfal and 
$V f a 2$, confer resistance to the fungal pathogen Venturia inaequalis inciting apple scab disease. Mol Plant-Microbe Interact 21:448-458.

Mozes-Koch R, Gover O, Tanne E, Peretz Y, Maori E, Chernin L and Sela I (2012) Expression of an entire bacterial operon in plants. Plant Physiol 158:1883-1892.

Nagamangala Kanchiswamy C, Sargent DJ, Velasco R, Maffei ME and Malnoy M (2015) Looking forward to genetically edited fruit crops. Trends Biotechnol 33:62-64.

Patocchi A, Frei A, Frey JE and Kellerhals M (2009) Towards improvement of marker assisted selection of apple scab resistant cultivars: Venturia inaequalis virulence surveys and standardization of molecular marker alleles associated with resistance genes. Mol Breed 24:337-347.

Peretz Y, Mozes-Koch R, Akad F, Tanne E, Czosnek H and Sela I (2007) A universal expression/silencing vector in plants. Plant Physiol 145:1251-1263.

Pyott DE, Sheehan E and Molnar A (2016) Engineering of CRISPR/Cas9-mediated potyvirus resistance in transgenefree Arabidopsis plants. Mol Plant Pathol 17:1276-88.

Sasaki S, Yamagishi N and Yoshikawa N (2011) Efficient virus-induced gene silencing in apple, pear and Japanese pear using Apple latente spherical virus vectors. Plant Methods 7:1-11.

Schouten HJ, Brinkhuis J, Burgh A, Schaart JG, Groenwold R, Broggini GAL and Gessler C (2014) Cloning and functional characterization of the Rvi15 (Vr2) gene for apple scab resistance. Tree Genet Genomes 10:251-260.

Silfverberg-Dilworth E, Besse S, Paris R, Belfanti E, Tartarini S, Sansavini S, Patocchi A and Gessler C (2005) Identification of functional apple scab resistance gene promoters. Theor Appl Genet 110:1119-1126.

Sutton TB (1996) Changing options for the control of deciduous fruit tree diseases. Annu Rev Phytopathol 34:527-547.

Vanblaere T, Szankowski I, Schaart J, Schouten H, Flachowsky H, Broggini GA and Gessler C (2011) The development of cisgenic apple plant. J Biotechnol 154:304-311.

Vanblaere T, Flachowsky H, Gessler C and Broggini GA (2014) Molecular characterization of cisgenic lines of apple 'Gala' carrying the Rvi6 scab resistance gene. Plant Biotechnol J 12:2-9.

Velasco R, Zharkikh A, Affourtit J, Dhingra A, Cestaro A, Kalyanaraman A, Fontana P, Bhatnagar SK, Troggio M, Pruss D et al. (2010) The genome of the domesticated apple (Malus domestica Borkh.). Nat Genet 42:833-841.
Vinatzer BA, Patocchi A, Gianfranceschi L, Tartarini S, Zhang HB, Gessler C and Sansavini S (2001) Apple contains receptor-like genes homologous to the Cladosporium fulvum resistance gene family of tomato with a cluster of genes cosegregating with $V f$ apple scab resistance. Mol PlantMicrobe Interact 14:508-515.

Weigl K, Wenzel S, Flachowsky H, Peil A and Hanke MV (2015) BpMADS4 on various linkage groups improves the utilization of the rapid cycle breeding system in apple. Plant Biotechnol J 13:246-258.

Williams EB and Shay JR (1957) The relationship of genes for pathogenicity and certain other characters in Venturia inaequalis (Cke.) Wint. Genetics 42:704-711.

Woo JW, Kim J, Kwon SI, Corvalán C, Cho SW, Kim H, Kim SG, Kim ST, Choe S and Kim JS (2015) DNA-free genome editing in plants with preassembled CRISP-Cas9 ribonucleopproteins. Nat Biotechnol 33:1162-1164.

$\mathrm{Xu}$ M and Korban SS (2002) A cluster of four receptor-like genes resides in the $V f$ Locus that confers resistance to apple scab disease. Genetics 162:1995-2006.

Yamagishi N, Sasaki S, Yamagata K, Komori S, Nagase M, Wada M, Yamamoto T and Yoshikawa N (2011) Promotion of flowering and reduction of a generation time in apple seedlings by ectopical expression of the Arabidopsis thaliana FT gene using the Apple latent spherical virus vector. Plant Mol Biol 75:193-204.

Yamagishi N, Kishigami R and Yoshikawa N (2014) Reduced generation time of apple seedlings to within a year by means of a plant virus vector: A new plant-breeding technique with no transmission of genetic modification to the next generation. Plant Biotechnol J 12:60-68.

Yin K, Han T, Liu G, Chen T, Wang Y, Yu AY and Liu Y (2015) A geminivirus-based guide RNA delivery system for CRISPR/Cas9 mediated plant genome editing. Sci Rep 5:14926.

Zhang L, Yao J, Withers J, Xin XF, Banerjee R, Fariduddin Q, Nakamura Y, Nomura K, Howe GA, Boland W, et al. (2015) Host target modification as a strategy to counter pathogen hijacking of the jasmonate hormone receptor. Proc Natl Acad Sci USA 112:14354-14359.

Associate Editor: Santiago Mora Garcia

License information: This is an open-access article distributed under the terms of the Creative Commons Attribution License (type CC-BY), which permits unrestricted use, distribution and reproduction in any medium, provided the original article is properly cited. 